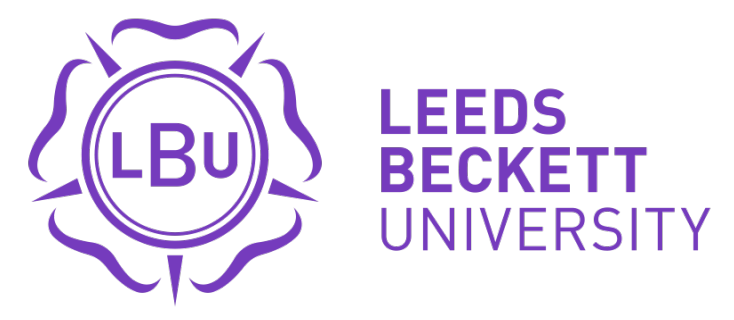

Citation:

Price, OJ and Hull, JH and Howatson, G and Robson-Ansley, P and Ansley, L (2015) Vitamin D and omega-3 polyunsaturated fatty acid supplementation in athletes with exercise-induced bronchoconstriction: a pilot study. Expert review of respiratory medicine, 9 (3). 369 - 378. ISSN 1747-6348 DOI: https://doi.org/10.1586/17476348.2015.1036032

Link to Leeds Beckett Repository record:

https://eprints.leedsbeckett.ac.uk/id/eprint/2037/

Document Version:

Article (Accepted Version)

The aim of the Leeds Beckett Repository is to provide open access to our research, as required by funder policies and permitted by publishers and copyright law.

The Leeds Beckett repository holds a wide range of publications, each of which has been checked for copyright and the relevant embargo period has been applied by the Research Services team.

We operate on a standard take-down policy. If you are the author or publisher of an output and you would like it removed from the repository, please contact us and we will investigate on a case-by-case basis.

Each thesis in the repository has been cleared where necessary by the author for third party copyright. If you would like a thesis to be removed from the repository or believe there is an issue with copyright, please contact us on openaccess@leedsbeckett.ac.uk and we will investigate on a case-by-case basis. 


\section{VITAMIN D AND OMEGA-3 POLYUNSATURATED FATTY ACID \\ SUPPLEMENTATION IN ATHLETES WITH EXERCISE-INDUCED \\ BRONCHOCONSTRICTION: A PILOT STUDY}

Oliver J. Price ${ }^{1,3}$, James H. Hull ${ }^{1,2,3}$, Glyn Howatson ${ }^{1,4}$, Paula Robson-Ansley ${ }^{1}$, Les Ansley ${ }^{1}$

${ }^{1}$ Faculty of Health and Life Sciences, Northumbria University, Newcastle upon Tyne, United Kingdom (UK).

${ }^{2}$ Department of Respiratory Medicine, Royal Brompton Hospital, UK.

${ }^{3}$ National Heart and Lung Institute, Imperial College London, London, UK.

${ }^{4}$ Water Research Group, School of Biological Sciences, North West University, Potchefstroom, South Africa

\section{Corresponding author:}

Dr. Les Ansley

Faculty of Health and Life Sciences, Northumbria University,

Newcastle, NE1 8ST.

Email: les.ansley@northumbria.ac.uk

Word count: 3849; Abstract count: 189

Running title: Dietary interventions in exercise-induced bronchoconstriction. 


\section{ABSTRACT}

Objective: The aim of this pilot study was to determine the combined effect of vitamin $\mathrm{D}$ and omega-3 PUFA supplementation on airway function and inflammation in recreational athletes with exercise-induced bronchoconstriction (EIB). Methods: Ten recreational athletes with EIB participated in a single blind, placebo-controlled trial over six consecutive weeks. All subjects attended the laboratory on three occasions. Each visit was separated by a period of 3 weeks; visit 1 (usual diet), visit 2 (placebo) and visit 3 (SMARTFISH ${ }^{\circledR}$ NutriFriend 2000;

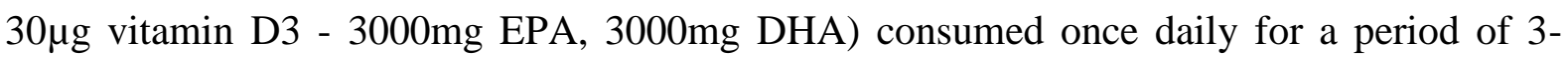
weeks. Venous blood was collected at the beginning of each trial to determine vitamin D status. Spirometry was performed pre and post eucapnic voluntary hyperpnea (EVH). Results: The $\Delta \mathrm{FEV}_{1} \max$ post $\mathrm{EVH}$ was not different between visits (usual diet: $-15.9 \pm$ 3.6\%; placebo: $-16.1 \pm 6.1 \%$; vitamin D + omega-3 PUFA: $-17.8 \pm 7.2 \%$ ). Serum vitamin D remained unchanged between visits. Conclusion: Vitamin D and omega-3 PUFA supplementation does not attenuate the reduction in lung function post EVH. These findings should be viewed as preliminary until the results of randomised controlled trials are made available.

Key words: Airway dysfunction, Exercise-induced bronchoconstriction, Inflammation, Omega-3 polyunsaturated fatty acids, Vitamin D. 


\section{INTRODUCTION}

3 Exercise-induced bronchoconstriction (EIB) describes the phenomenon of acute, transient

4 airway narrowing in association with physical activity [1] and is highly prevalent in both

5 recreational and elite level athletes [2,3]. Although the precise pathogenesis of EIB is not

6 completely understood, it is generally acknowledged that exercise hyperpnea initiates

7 bronchoconstriction by inducing osmotic changes at the distal airway surface [4]. This

8 precipitates the release of pro-inflammatory mediators including histamine, neuropeptides,

9 cytokines, cysteinyl leukotrienes and prostaglandins, ultimately resulting in airway smooth

10 muscle contraction [5]. In the chronic setting, repeated, prolonged periods of exercise

11 hyperpnea have been associated with injury-repair cycling of the airway epithelium resulting

12 in smooth muscle remodelling [6,7] and the development of EIB in athletes [2].

13 The mainstay of treatment for EIB consists of pharmacological medication (e.g. short acting inhaled beta-2 agonists (SABA)) [1]. However, there is accumulating evidence that nonpharmacological interventions, such as dietary modification, may have utility in the treatment of EIB in athletes [8]. This is pertinent given the possible side effects of chronic beta- 2 agonist therapy (e.g. development of tachyphlaxis and degenerative changes in lung function)

18 [9]. One of the most promising dietary interventions is fish oil supplementation. Specifically, omega-3 polyunsaturated fatty acids (PUFA) (eicosapentaenoic acid (EPA) and docosahexaenoic acid (DHA)) have previously been shown to attenuate airway inflammation and the bronchoconstrictor response to exercise hyperpnea $[10,11]$. The purported therapeutic effect of omega-3 PUFA for the treatment of EIB in athletes is biologically plausible; however the findings to date remain equivocal [10-16]. The proposed mechanism of omega-3 PUFA protecting against EIB consists of EPA and DHA competitively inhibiting arachidonic acid metabolism and therefore reducing the generation of pro-inflammatory leukotrienes, prostaglandins and cytokine production from inflammatory cells [17]. 
Indeed, other dietary interventions may also be important. Recently, epidemiological studies have highlighted a direct association between vitamin D deficiency and the incidence and severity of asthma [18]. Although the evidence is sparse, low serum vitamin D levels have previously been associated with reduced lung function and increased airways hyper-reactivity to exercise in asthmatic children with EIB [19]. Mechanisms by which vitamin D may prevent EIB are likely multifactorial. The vitamin D receptor is expressed in most tissues and it has been proposed that vitamin D deficiency may result in an increase in mast cells, histamine release and apoptosis [20,21]. Furthermore, a reduction in the expression of proinflammatory interleukins (i.e. interleukin (IL)-13) associated with bronchoconstriction has been observed [22]. Vitamin D receptors in respiratory epithelial cells and bronchial smooth muscle have also been reported to regulate the expression of genes implicated in the pathogenesis of asthma [23] and smooth muscle proliferation (i.e. airway remodelling) [24]. Consequently, as vitamin D deficiency may play a role in the pathogenesis of lung disease, supplementation may present a novel preventative and/or therapeutic strategy for athletic 41 individuals with EIB.

The principal aim of this pilot study was to evaluate the combined effect of a commercially available vitamin D and omega-3 PUFA supplement (SMARTFISH ${ }^{\circledR}$ NutriFriend 2000), on airway function in recreational athletes with EIB. We hypothesised that lower levels of vitamin $\mathrm{D}$ would be associated with reduced lung function, and that vitamin $\mathrm{D}$ and omega-3 PUFA supplementation would attenuate airway inflammation and bronchoconstriction following an indirect bronchoprovocation challenge. Eucapnic voluntary hyperpnea (EVH) was selected as the bronchoprovocation challenge since it is the test currently favoured by the International Olympic Committee-Medical Commission (IOC-MC) for diagnosing EIB in elite athletes [25]. 


\section{METHODS}

\section{Preliminary screening}

54 One hundred and one endurance trained recreational athletes (mean \pm SD: $6 \pm 1$ hours training/week) were recruited and subsequently tested for EIB via a EVH challenge

56 (described below). Sixteen athletes (17\%) were positive for EIB (i.e. $\geq 10 \%$ fall in FEV 1 post

57 EVH) and thus considered eligible for participation.

\section{Study population}

59 Ten athletes (runners, cyclists and triathletes) (male: $n=9$ ) with EIB (63\%) agreed to take 60 part in the study. All subjects were non-smokers, free from respiratory, cardiovascular, metabolic and psychiatric disease, and any other significant medical condition except mild asthma. Four subjects had a previous physician-based diagnosis of clinical asthma and were prescribed a SABA; two of the four were also prescribed maintenance-inhaled corticosteroid.

\section{Experimental design}

65

66

67

The study was conducted as a single blind placebo-controlled trial over six consecutive weeks (June - September, United Kingdom). A randomised double-blind crossover design was not practical due to the half-life ( 15 days) of vitamin D [26] (i.e. approximately 6month wash-out period) and the effect of seasonal variation on airway calibre in atopic individuals [27]. All subjects were required to attend the laboratory on three occasions. Each visit was separated by a period of 3 weeks; visit 1 (usual diet), visit 2 (placebo; matching the treatment beverage for appearance, taste, quantity and packaging) and visit 3 (treatment; vitamin D + omega-3 PUFA consisting of a $600 \mathrm{ml}$ fruit and berry flavoured beverage -

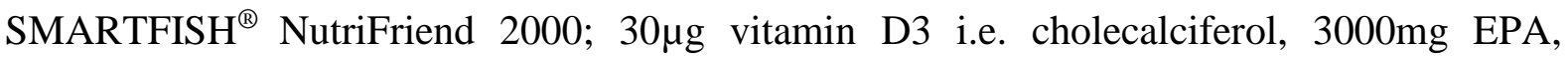
3000mg DHA) consumed once daily for a period of 3-weeks. SMARTFISH ${ }^{\circledR}$ provided 
documented evidence (i.e. quality assurance) of the content of both placebo and experimental beverages.

Subjects arrived at the laboratory $1 \mathrm{~h}$ postprandial at a similar $( \pm 1 \mathrm{~h})$ time of day following their usual diet. At visit 1 an assessment of respiratory health and evaluation of allergy status was determined via completion of the Allergy Questionnaire for Athletes (AQUA) and aeroallergen skin prick testing. For all visits, venous blood was collected at the beginning of each trial to determine serum vitamin D status. Spirometry was performed pre- and post-EVH provocation. Airway inflammation was determined via fractional exhaled nitric oxide $\left(\mathrm{FE}_{\mathrm{NO}}\right)$ (indirect marker for up-regulation of airway inflammation) pre- and $30 \mathrm{~min}$ post-EVH. Urine samples were obtained pre- and $60 \mathrm{~min}$ post-EVH for cysteinyl leukotriene (LTE4) and prostaglandin $\left(9 \alpha, 11 \beta\right.$ - prostaglandin $\left.\mathrm{F}_{2}\right)$ quantification (markers of airway inflammation and mast cell activation, respectively). With the exception of AQUA and aeroallergen skin prick testing, all visits were replicated precisely on subsequent visits (Figure 1).

Subjects were excluded from follow-up assessment if changes in training and/or health status, respiratory tract infection, allergen or sunlight exposure were reported between visits.

90 Subjects were asked to abstain from dietary supplements (e.g. vitamins and anti-oxidants) throughout the duration of the study and SABA and inhaled corticosteroid medication for 24 and $72 \mathrm{~h}$, respectively, prior to each visit. Northumbria University ethics committee approved all tests and procedures, and all subjects provided written informed consent for

94 experimentation with human subjects.

\section{Atopic Status}

96 Sensitivity to seven common airborne allergens (early blossom tree, mid blossom tree, grass,

97 weed, mould, cat and dust mite) were assessed via skin prick testing [28]. A subject was classified as atopic if, in the skin prick test, at least 1 allergen caused a wheal of at least $3 \mathrm{~mm}$ 
99 in diameter, in the presence of a negative saline control and positive histamine. Subjects also

100 completed AQUA to assess allergic symptoms [29]. An athlete was considered to be allergic

101 if they presented with a positive skin prick test and a positive AQUA score $\geq 5$.

\section{Pulmonary function}

\section{Spirometry}

104 Lung function was assessed by forced flow-volume spirometry (MicroLoop ML3535;

105 Cardinal Health, UK) [30].

\section{Eucapnic voluntary hyperpnea}

107 Bronchoprovocation challenge testing with EVH was performed as described previously

108 [31,32]. In brief, subjects were required to inhale a mixture of dry compressed gas $\left(21 \% \mathrm{O}_{2}\right.$,

$1095 \% \mathrm{CO}_{2}$, balance $\mathrm{N}_{2}$ ) at a ventilation rate equivalent to approximately $85 \%$ maximal

110 voluntary ventilation (MVV)-calculated as $30^{*} \mathrm{FEV}_{1}$ for a period of $6 \mathrm{~min}$. Subjects viewed

111 their ventilatory volume in real-time in order to ensure they maintained the target level. A

112 positive diagnosis for EIB was defined by a post-EVH reduction in $\mathrm{FEV}_{1}$ of $\geq 10 \%$ compared

113 to resting spirometry.

\section{Airway inflammation}

115 Fraction of exhaled nitric oxide $\left(\mathrm{FE}_{\mathrm{NO}}\right)$ was the first test performed during each visit and

116 measured using a hand-held measuring device (NIOX MINO $\left.{ }^{\circledR}\right)($ Aerocrine AB, Stockholm,

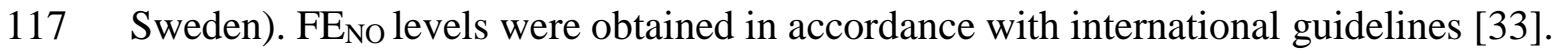

\section{Vitamin D status}

119 The Elecsys Total 25-hydroxyvitamin D assay (Roche Diagnostics GmbH, Germany) was

120 used for the quantative determination of total serum 25-hydroxyvitamin $\mathrm{D}(25(\mathrm{OH}) \mathrm{D})$

121 (nmol/L) [34]. Intra-assay coefficient of variation was $<10 \%$. Vitamin D status was classified 
122 according to previous recommendations as sufficient: $75-100 \mathrm{nmol} / \mathrm{L}$; insufficient: $50-75$

$123 \mathrm{nmol} / \mathrm{L}$; deficient: < $50 \mathrm{nmol} / \mathrm{L}[19,35]$.

\section{Urinary inflammatory markers}

125 Enzyme immunoassays of $\mathrm{LTE}_{4}$ and $9 \alpha, 11 \beta$ - prostaglandin $\mathrm{F}_{2}$ were performed in serially 126 diluted urine (Cayman Chemical Company, Ann Arbor, MI) as previously described [36,37].

127 Inter- and intra-assay coefficient of variation was $<10 \%$. All data were normalised and 128 presented as nanograms of excreted mediator per millimole of creatinine. Creatinine analyses were performed using a modification of Jaffe's creatinine protocol [38].

\section{Nutrient intake and compliance}

131 Subjects were instructed to maintain their usual diet (maximum of one fish meal per week) 132 and physical activity levels throughout the duration of the study. Adherence to treatment 133 regimens was monitored by athletes documenting the time and date of consumption and 134 returning any supplements that were not consumed. In accordance with comparable research a compliance of $\geq 90 \%$ was considered acceptable [36].

\section{Statistical analysis}

137 Normality of data was assessed using a Kolmogorov-Smirnov test and Levene's test to check

138 for homogeneity of variance between groups. A two-way repeated measures analysis of 139 variance (ANOVA) was used to analyse within subject effects. Mauchly's test was conducted 140 to determine if sphericity was violated. If sphericity was violated, the repeated measures 141 ANOVA was corrected using a Greenhouse-Geisser adjustment factor. A Bonferroni post hoc 142 analysis was employed for multiple comparisons $(P<0.05)$. A one way repeated measures 143 ANOVA was employed where relevant and relationships between variables were determined

144 via liner regression analysis (Pearson correlation coefficients). $\mathrm{AUC}_{0-20 \mathrm{~min}}$ was calculated by 145 the trapezoidal method and expressed as percentage fall in $\mathrm{FEV}_{1}$. Data was analysed using 
146 PASW Statistics 21 statistical software package (SPSS Inc., Version 21, Chicago, IL) and 147 GraphPad Prism Version 5.0 (GraphPad Software, San Diego, California, USA). Data are 148 expressed as mean $( \pm \mathrm{SD})$ and significance was set at $P<0.05$. 


\section{RESULTS}

151 Baseline characteristics, allergy and pre-challenge lung function

152 Ten recreational athletes (male: $n=9$ ) completed the study. Subjects' characteristics are

153 presented in Table 1. Eight athletes were atopic to skin prick testing and eight had a positive

$154(\geq 5)$ AQUA questionnaire. Seven athletes with a positive AQUA questionnaire were also 155 atopic and therefore considered allergic. Five subjects reported respiratory symptoms (e.g. 156 cough, wheeze, dyspnea etc.) in association with exercise. All pulmonary function measures 157 were within normal predicted limits with no evidence of airflow obstruction. In addition, no 158 difference in resting lung function was observed between visits $(P>0.05)$ (Table 2).

\section{Compliance to treatment regimens}

160 Excellent adherence to treatment regimens was reported for placebo and vitamin D + omega1613 PUFA $(99.5 \pm 1.1 \%$ and $98.5 \pm 3.4 \%)$ diets, respectively $(P>0.05)$.

\section{Airway response to eucapnic voluntary hyperpnea}

163 Similar ventilation rates were achieved between all visits (usual diet: $105 \pm 25 \mathrm{~L}^{\mathrm{min}}{ }^{-1}$;

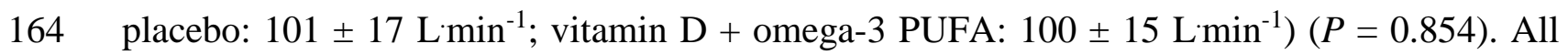
165 athletes maintained $>60 \%$ MVV throughout EVH thus achieving test validation [39]. The $166 \Delta \mathrm{FEV}_{1} \max$ post-EVH was no different between visits (usual diet: $-15.9 \pm 3.6 \%$; placebo:$16716.1 \pm 6.1 \%$; vitamin D + omega-3 PUFA: $-17.8 \pm 7.2 \%)(P=0.719)$. No difference was 168 observed in the reduction in $\mathrm{FEV}_{1}$ between conditions at any time point $(P>0.05)$ (Figure 2)

169 (Table 3). Furthermore, no difference was observed for $\mathrm{AUC}_{0-20}$ min $\%$ fall in $\mathrm{FEV}_{1}$ between 170 visits (usual diet: $198.0 \pm 75.9 \%$; placebo: $239.7 \pm 99.4 \%$; vitamin $\mathrm{D}+$ omega-3 PUFA: $171256.9 \pm 135.5 \%)(P=0.455)$. 


\section{Vitamin D status}

173 At visit one (usual diet), three athletes (30\%) had sufficient levels of vitamin $\mathrm{D}$, five were

174 insufficient, and two were deficient. At visit two (placebo), two athletes were sufficient, six

175 were insufficient and two were deficient. At visit three (vitamin D + omega-3 PUFA), three

176 were sufficient, six were insufficient and one was deficient. No difference in serum vitamin D

177 was observed between visits (usual diet: $64.2 \pm 17.4$ nmol.L $\mathrm{L}^{-1}$; placebo: $65.1 \pm 16.5 \mathrm{nmol} . \mathrm{L}^{-1}$;

178 vitamin D + omega-3 PUFA: $69.0 \pm 16.9$ nmol.L $\mathrm{L}^{-1}(P=0.798)$. In addition, change in serum

179 vitamin $\mathrm{D}$ status between visits did not correlate with $\triangle \mathrm{FEV}_{1} \max (\mathrm{r}=0.11 ; P=0.559)$.

\section{Airway inflammation}

181 No difference in $\mathrm{FE}_{\mathrm{NO}}$ was observed pre-EVH between visits (usual diet: $28 \pm 16 \mathrm{ppb}$;

182 placebo: $31 \pm 23 \mathrm{ppb}$; vitamin $\mathrm{D}+$ omega-3 PUFA: $37 \pm 27 \mathrm{ppb})(P=0.182)$ or post-EVH

183 between visits (usual diet: $27 \pm 19$ ppb; placebo: $25 \pm 19 p p b$; vitamin D + omega-3 PUFA: 28

$184 \pm 18 \mathrm{ppb})(P=0.834)$. However, a reduction in $\mathrm{FE}_{\mathrm{NO}}$ post-EVH was observed within 185 condition for placebo (-20.1\%) and vitamin D + omega-3 PUFA (-28.9\%), respectively $186(P<0.05)$ (Figure 3).

\section{Urinary inflammatory markers}

\section{Cysteinyl leukotriene $\mathrm{LTE}_{4}$}

189 LTE4 was higher pre-EVH following vitamin D + omega-3 PUFA: $104.1 \pm 26.7 \mathrm{ng} / \mathrm{mmol}$

190 creatinine compared to both usual diet: $72.6 \pm 16.6 \mathrm{ng} / \mathrm{mmol}$ creatinine and placebo: $72.6 \pm$ $19122.9 \mathrm{ng} / \mathrm{mmol}$ creatinine $(P<0.05)$. No difference was observed between usual diet and 192 placebo $(P>0.05)$. $\mathrm{LTE}_{4}$ was higher post-EVH following vitamin D + omega-3 PUFA: $99.1 \pm$ $19329.2 \mathrm{ng} / \mathrm{mmol}$ creatinine compared to placebo: $61.0 \pm 13.7 \mathrm{ng} / \mathrm{mmol}$ creatinine $(P=0.007)$.

194 No difference was observed between usual diet and placebo or usual diet and vitamin D + 
195 omega-3 PUFA respectively $(P>0.05)$ (Figure 4). $\mathrm{LTE}_{4}$ did not correlate with $\Delta \mathrm{FEV} \mathrm{V}_{1} \max (\mathrm{r}=$ $196 \quad 0.30 ; P=0.107)$.

$1979 \alpha, 11 \beta-$ prostaglandin $F_{2}$

198 No difference in $9 \alpha, 11 \beta$ - prostaglandin $\mathrm{F}_{2}$ was observed pre-EVH between visits (usual diet: $19988.9 \pm 59.1 \mathrm{ng} / \mathrm{mmol}$ creatinine; placebo: $82.8 \pm 37.6 \mathrm{ng} / \mathrm{mmol}$ creatinine; vitamin $\mathrm{D}+$ 200 omega-3 PUFA: $79.2 \pm 43.7 \mathrm{ng} / \mathrm{mmol}$ creatinine) or post-EVH between visits (usual diet: 201 (usual diet: $104.0 \pm 41.7 \mathrm{ng} / \mathrm{mmol}$ creatinine; placebo: $101.1 \pm 56.8 \mathrm{ng} / \mathrm{mmol}$ creatinine; 202 vitamin D + omega-3 PUFA: $90.3 \pm 48.0 \mathrm{ng} / \mathrm{mmol}$ creatinine) (P>0.05) (Figure 4). A 203 correlation was observed between $9 \alpha, 11 \beta$ - prostaglandin $\mathrm{F}_{2}$ post-EVH and $\Delta \mathrm{FEV} \mathrm{F}_{1} \max (\mathrm{r}=$ $204 \quad 0.45 ; P=0.017)$ 


\section{DISCUSSION}

207 This study has shown, contrary to our hypothesis, that the combination of vitamin D and 208 omega-3 PUFA supplementation over a 3-week period does not reduce markers of airway 209 inflammation or attenuate the reduction in lung function post EVH in recreational athletes 210 with EIB. Furthermore, serum vitamin D status does not appear to correspond directly to the

211 severity of bronchoconstriction following indirect bronchoprovocation. The study design and 212 intervention of the present study was based on the premise that dietary modification with a 213 commercially available self-administrated supplement would be pragmatic and overall 214 applicable to 'real-life'.

215 Vitamin D deficiency (serum 25-hydroxyvitamin D $<50 \mathrm{nmol} . \mathrm{L}^{-1}$ ) has previously been 216 associated with a reduction in lung function and increased reactivity to exercise in asthmatic 217 children with EIB [19]. However, the precise role of vitamin D in the pathogenesis of EIB 218 has yet to be determined. In the current study $20 \%(2 / 10)$ of athletes presented with vitamin

219 D deficiency following their usual diet. This is in contrast to previous findings where 51\% 220 (23/45) of asthmatic children with EIB were vitamin D deficient [19]. The dissociation 221 between studies is somewhat surprising, however supports the notion that physical activity is 222 directly related to the level of sun light exposure [40]. However, it is important to acknowledge that the comparison of prevalence estimates of vitamin D deficiency between studies may be confounded by the population studied (i.e. adults versus children). In addition, as the current study was conducted in the summer months (June - September, United

226 Kingdom), this may, in part, explain the limited number of athletes presenting with vitamin D

227 deficiency. However, it must be acknowledged that the long half-life of vitamin D [26] combined with controlling environmental factors (e.g. sunlight exposure and diet) limits the standardisation of vitamin D trials in vivo (i.e. human studies). Nevertheless, further work is 
230 required to fully determine the extent of vitamin $\mathrm{D}$ deficiency and thus requirement of 231 supplementation in athletic individuals.

232 In the present study adherence to the treatment regimens was high, however no difference 233 was observed in serum vitamin D following supplementation. Previous epidemiological 234 studies have highlighted a positive correlation between lung function and serum vitamin D 235 levels [19,41], whereas others have shown no association [42]. However, observational 236 studies do not confirm causality. Our findings show a poor relationship between vitamin D 237 status and severity of bronchoconstriction, thus disputing a direct association. These findings 238 are supported by a recent comparable study demonstrating no effect of vitamin D 239 supplementation in children with mild asthma [43]. However, a general consensus regarding 240 the optimal vitamin D dose has yet to be established (see recent review by Owens et al. [44]).

241 It is therefore reasonable to speculate that the dose employed within the current study (30 $\mu \mathrm{g}$ /day) or indeed length of supplementation was not sufficient to elicit a therapeutic effect.

243 Thus, the optimal level of vitamin D supplementation remains elusive and clinical trials are

244 required before informed recommendations can be employed.

245 Mickleborough et al. [10,11] previously reported that omega-3 PUFA (3.2g/day EPA and $2462.2 \mathrm{~g} /$ day DHA) derived from fish oil results in a reduction in markers of airway inflammation 247 (e.g. LTE 4 and $9 \alpha, 11 \beta$ - prostaglandin $\mathrm{F}_{2}$ ) and an attenuated bronchoconstrictor response 248 following exercise in EIB and asthmatic patients, respectively. More recently, similar 249 findings have been reported by the same group following EVH bronchoprovocation [12,36]. 250 Although Arms et al. [16] also observed a 50\% inhibition of total leukotriene count in 251 peripheral blood in mild asthmatics following 10 weeks of daily fish oil supplementation 252 (3.2g EPA and 2.2g DHA), in agreement with our findings no change was observed in $253 \Delta \mathrm{FEV}_{1}$ max post indirect bronchoprovocation. In further support of this concept, Brannan et 254 al. [15] recently found that a 3-week period of omega-3 supplementation (4.0g/day EPA and 
2.0g/day DHA) does not improve bronchial hyper-responsiveness to mannitol or inhibit urinary excretion of mast cell mediators in adults with mild-moderate asthma.

257 This observation is comparable with findings from the present study where no difference was 258 observed in urinary $9 \alpha, 11 \beta$ - prostaglandin $\mathrm{F}_{2}$ between visits. Although urinary $\mathrm{LTE}_{4}$ 259 increased pre and post EVH following vitamin D + omega-3 PUFA, the majority of athletes 260 within our cohort were atopic $(80 \%)$ and allergic (70\%), and thus any potential anti261 inflammatory effect of vitamin D and omega-3 PUFA may have been counteracted by the variation in allergen exposure (e.g. pollen count, house dust mite etc.) between visits [27]. In keeping with our findings however, Moreira et al. [45] observed no difference in $\mathrm{FE}_{\mathrm{NO}}$

264 following short-term dietary supplementation with omega-3 PUFA in woman with stable 265 asthma.

266 Our finding of a correlation between $\Delta \mathrm{FEV}_{1} \max$ and urinary excretion of $9 \alpha, 11 \beta$ prostaglandin $\mathrm{F}_{2}(\mathrm{P}<0.05)$ further supports the role of mast cells in EIB [37]. Although the urine sampling time-points post challenge were not identical, similar to Kippelen et al. [37] no association existed between $\triangle \mathrm{FEV}_{1} \mathrm{max}$ and urinary excretion of $\mathrm{LTE}_{4}$. This observation could suggest that $9 \alpha, 11 \beta$ - prostaglandin $F_{2}$ is a more sensitive marker of EIB in atopic individuals than $\mathrm{LTE}_{4}$, which warrants further investigation.

272 Although Mickleborough and Rundell [17] have highlighted statistical limitations to explain the inconsistency in results between studies [17], the majority of trials have consisted of a comparable sample size to the present study $[10,11,16]$. However, it should be acknowledged that the diagnostic methodology used to quantify the extent of bronchoconstriction often varies between studies [10-12,15]. Furthermore, it has previously been shown that a poor relationship exists between indirect bronchoprovocation challenges (i.e. exercise and EVH) $[46,47]$. It is therefore possible that the purported therapeutic effect of treatment varies according to the specific bronchoprovocation challenge employed. 
280 Nonetheless, the disparities in findings are still somewhat surprising given the similarities in 281 study design, population, sample size and similar dose of the respective interventions

$282[10,11,16]$. Whilst the form of vitamin D and omega-3 PUFA administration in the present 283 study differed from previous research, there is currently no consensus in the literature to 284 suggest that the absorption or indeed effect of supplementation significantly varies according 285 to the form of consumption (i.e. encapsulated supplement versus commercially available 286 nutritional beverage). However, it should be acknowledged that in contrast to previous work $287[6,10,14,19,40,41]$ equal quantities of EPA and DHA (3.0g/day) were employed in the 288 current study. It is therefore possible that EPA may be more important than DHA in 289 attenuating EIB. This theory is consistent with a previous pilot study by Head et al. [13] 290 where supplementation with $4.0 \mathrm{~g} /$ day of DHA did not attenuate bronchoconstriction or 291 airway inflammation in asthmatic patients following EVH. Moreover, a recent mouse model 292 of asthma observed pro-inflammatory effects following the consumption of DHA over a six 293 week period [48].

294 Overall however, the results of the present study support the current recommendation by the 295 American Thoracic Society that the evidence is not currently strong enough to confirm that 296 omega-3 PUFA's are effective in the large majority of patients with EIB [1].

297 Pertinent to the present study and previous research [10-12,16,36], poor short-term test re-test 298 clinical reproducibility of indirect bronchoprovocation (i.e. exercise and EVH) $[49,50]$ has 299 recently been observed in patients with mild EIB. Therefore, although the combination of 300 vitamin $\mathrm{D}$ and omega-3 PUFA does not appear to attenuate the $\triangle \mathrm{FEV}_{1 \mathrm{max}}$ post 301 bronchoprovocation, the inherent variability of a test employed to determine changes in lung 302 function should be considered when advocating the efficacy of a treatment intervention to 303 avoid masking or overestimating the proposed therapeutic benefit. Likewise, the use of $\mathrm{FE}_{\mathrm{NO}}$ 
as a marker of airway inflammation may be confounded given the high ventilatory demand of

305 EVH (i.e. exhaled nitric oxide often falls from baseline values even when EIB is confirmed).

\section{Methodological considerations / future research}

307 Although this study is the first interventional trial to address the impact of combining vitamin

308 D and omega-3 PUFA supplementation in athletic individuals with EIB, there are a number

309 of important considerations. Firstly, given the small sample size of the cohort, the results

310 should be viewed with some caution. Whilst we are confident that false negative results (i.e.

311 type II error) have not been reported, further work with a larger sample size is still required to

312 provide a definitive answer. Secondly, the optimal level of vitamin D supplementation

313 remains elusive and clinical trials are required before informed recommendations can be

314 employed. Once established, randomised controlled trials are required to determine the

315 individual and combined efficacy of vitamin D and omega-3 PUFA for the treatment of EIB

316 in athletes. Whilst highly speculative, the possibility exists that the lipophilic properties of

317 vitamin D may compete with omega-3 PUFA by an unknown mechanism. Thirdly, to

318 understand the mechanism of action of specific interventions, future studies should assess

319 nutritional deficiencies (i.e. vitamin D and omega-3 PUFA status) prior to study entry and

320 recruit homogenous cohorts of athletes according to severity of disease and specific clinical

321 phenotypes (e.g. asthma, EIB, airway hyper-responsiveness, atopy etc.) rather than 'pooling'

322 heterogeneous cohorts. Finally, the longitudinal impact of vitamin D and/or omega-3 PUFA

323 supplementation has yet to be established. Conducting randomised double-blind crossover

324 design studies (acknowledging the limitations of vitamin D washout) may provide value in 325 this setting. 


\section{Conclusion}

327 In conclusion, this pilot study has shown that a 3-week period of vitamin D and omega-3

328 PUFA supplementation does not reduce markers of airway inflammation nor attenuate the

329 reduction in lung function post EVH. In addition, vitamin D status does not appear to

330 correspond directly to the severity of bronchoconstriction in recreational athletes with EIB.

331 However, these findings should be viewed as preliminary until the results of randomised

332 controlled trials are made available.

333 
- Vitamin D deficiency has previously been associated with the development and severity of asthma, with low serum vitamin D levels associated with reduced lung function and increased reactivity to exercise in children with EIB.

- Omega-3 PUFA supplementation has been shown to attenuate airway inflammation and bronchoconstriction following indirect bronchoprovocation.

- The aim of this pilot study was to determine the combined effect of acute vitamin D and omega-3 PUFA supplementation on airway function in recreational athletes with EIB.

- The combination of vitamin D and omega-3 PUFA supplementation does not reduce markers of airway inflammation nor attenuate the reduction in lung function following EVH.

- Serum vitamin D status does not appear to directly correspond to the severity of bronchoconstriction.

- The inherent variability of a test (i.e. indirect bronchoprovocation) employed to determine changes in lung function should be considered when advocating the efficacy of a treatment intervention to avoid masking or overestimating the proposed therapeutic benefit.

- Further work is required to determine the individual and combined effect of omega-3 PUFA and vitamin D as a non-pharmacological treatment for EIB. The findings of the present study should be viewed as preliminary until the results of randomised controlled trials are made available. 


\section{TABLE HEADINGS}

366 Table 1: Subject clinical characteristics.

367

368 Definitions of abbreviations: BMI, body mass index.

369

370 Table 2: Baseline pulmonary function.

371

372 Definitions of abbreviations: FEV $_{1}$, forced expiratory volume in $1^{\text {-s }}$; FVC, forced vital 373 capacity; $\mathbf{P E F}$, peak flow rate.

374

375 Table 3: Baseline lung function and response to eucapnic voluntary hyperpnea.

376 Definitions of abbreviations: $\mathbf{F E V}_{\mathbf{1}}$, forced expiratory volume in $1^{-\mathrm{s}}$ 
Table 1.

\begin{tabular}{|c|c|c|c|c|c|c|c|c|c|c|}
\hline Subject & $\begin{array}{c}\text { Sex } \\
(M: F)\end{array}$ & $\begin{array}{c}\text { Age } \\
\text { (years) }\end{array}$ & $\begin{array}{c}\text { Height } \\
\text { (cm) }\end{array}$ & $\begin{array}{c}\text { Weight } \\
\text { (kg) }\end{array}$ & 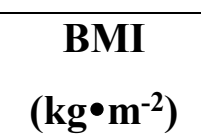 & $\begin{array}{c}\text { Training } \\
\left(\text { hrs }^{\bullet} \mathbf{w k}^{-1}\right)\end{array}$ & $\begin{array}{c}\text { Physician } \\
\text { diagnosed asthma }\end{array}$ & Medication & $\begin{array}{l}\text { Self-report } \\
\text { symptoms }\end{array}$ & Allergy \\
\hline 1 & $\mathrm{M}$ & 42 & 177.7 & 90.3 & 28.6 & 6 & No & Nil & Asymptomatic & No \\
\hline 2 & M & 27 & 185.6 & 87.4 & 25.4 & 6 & No & Nil & Asymptomatic & No \\
\hline 3 & M & 36 & 178.5 & 72.5 & 22.8 & 6 & No & Nil & Asymptomatic & Yes \\
\hline 4 & M & 28 & 181.3 & 79.4 & 24.2 & 6 & No & Nil & Asymptomatic & Yes \\
\hline 5 & M & 48 & 173.7 & 75.6 & 25.1 & 6 & No & Nil & Asymptomatic & Yes \\
\hline 6 & M & 28 & 177.0 & 78.8 & 25.2 & 6 & Yes & $\mathrm{SABA}+\mathrm{ICS}$ & Symptomatic & Yes \\
\hline 7 & $\mathrm{~F}$ & 42 & 166.6 & 64.2 & 23.1 & 6 & Yes & SABA & Symptomatic & No \\
\hline 8 & M & 39 & 177.9 & 88.7 & 28.0 & 6 & Yes & $\mathrm{SABA}+\mathrm{ICS}$ & Symptomatic & Yes \\
\hline 9 & M & 34 & 181.1 & 72.7 & 22.2 & 6 & Yes & $\mathrm{SABA}+\mathrm{ICS}$ & Symptomatic & Yes \\
\hline 10 & M & 24 & 183.3 & 84.5 & 25.1 & 4.5 & No & Nil & Symptomatic & Yes \\
\hline Total & $9: 1$ & $35 \pm 8$ & $178.3 \pm 5.5$ & $79.4 \pm 8.4$ & $25.0 \pm 2.1$ & $6 \pm 1$ & $4 / 10$ & $4 / 10$ & $5 / 10$ & $7 / 10$ \\
\hline
\end{tabular}


Table 2.

Baseline pulmonary function

\begin{tabular}{|c|c|c|c|}
\hline & Visit 1 & Visit 2 & Visit 3 \\
\hline & Usual diet & Placebo & Vitamin D + Omega-3 \\
\hline $\mathrm{FEV}_{1}(\mathrm{~L})$ & $4.04 \pm 0.85$ & $4.12 \pm 0.77$ & $4.00 \pm 0.80$ \\
\hline $\mathrm{FEV}_{1}(\%$ predicted $)$ & $96.5 \pm 15.4$ & $98.4 \pm 12.0$ & $95.4 \pm 12.2$ \\
\hline $\mathrm{FVC}(\mathrm{L})$ & $5.61 \pm 0.81$ & $5.69 \pm 0.78$ & $5.61 \pm 0.86$ \\
\hline FVC (\% predicted) & $111.6 \pm 10.7$ & $113.1 \pm 9.5$ & $111.2 \pm 10.4$ \\
\hline $\mathrm{FEV}_{1} / \mathrm{FVC}(\%)$ & $71.4 \pm 5.4$ & $71.9 \pm 4.2$ & $71.0 \pm 4.7$ \\
\hline PEF (L/min) & $552.4 \pm 103.3$ & $569.5 \pm 85.6$ & $556.1 \pm 107.5$ \\
\hline PEF (\% predicted) & $97.7 \pm 13.7$ & $100.6 \pm 7.9$ & $97.9 \pm 11.5$ \\
\hline
\end{tabular}


Table 3.

\begin{tabular}{ccccc}
\hline \multicolumn{2}{c}{ Baseline } & \multicolumn{2}{c}{$\Delta$ FEV 1 max } \\
\hline Subject & Visit 1: FEV $1 \%$ predicted $)$ & Visit 1: Usual diet & Visit 2: Placebo & Visit 3: Vitamin D + Omega-3 PUFA \\
\hline 1 & 87.0 & -19.6 & -12.5 & -17.5 \\
2 & 104.9 & -17.2 & -20.8 & -20.5 \\
3 & 102.6 & -11.5 & -20.1 & -16.5 \\
4 & 95.2 & -12.9 & -13.2 & -14.7 \\
5 & 89.8 & -12.1 & -12.1 & -7.5 \\
6 & 130.0 & -13.6 & -9.0 & -12.0 \\
7 & 80.2 & -14.4 & -17.6 & -14.7 \\
8 & 95.8 & -16.8 & -9.4 & -25.1 \\
9 & 104.4 & -18.2 & -16.9 & -16.1 \\
10 & 75.4 & -22.6 & -28.9 & -33.4 \\
\hline Mean \pm SD & $96.5 \pm 15.4$ & $-15.9 \pm 3.6$ & $-16.1 \pm 6.1$ & $-17.8 \pm 7.2$ \\
\hline
\end{tabular}


382 Figure 1. Schematic depicting the experimental design.

383 Definitions of abbreviations: AQUA, The Allergy Questionnaire for Athletes; EIB, 384 exercise-induced bronchoconstriction; $\mathbf{F E V}_{1}$, forced expiratory volume in $1^{-s} ; \mathbf{E V H}$; 385 Eucapnic voluntary hyperpnea; FENo, fractional exhaled nitric oxide.

386

387 Figure 2. Percentage change in $\mathrm{FEV}_{1}$ post EVH between visits. Usual diet (open circles); 388 placebo (closed circles); vitamin D + omega-3 PUFA (closed triangles). Broken horizontal 389 line represents abnormal lung function (i.e. $\geq 10 \%$ fall in $\mathrm{FEV}_{1}$ ). Placebo SD error lines 390 omitted to improve clarity of graph.

Figure 3. Fractional exhaled nitric oxide ( $\left.\mathrm{FE}_{\mathrm{NO}}\right)$ concentration $(\mathrm{ppb})$ pre-EVH (closed bar) and 30 min post-EVH (open bar) between visits. " denotes significant difference within condition between pre- and post-EVH $(P<0.05)$

Figure 4. Panel a). Urinary $\mathrm{LTE}_{4}$ concentration pre EVH (closed bar) and 60 min post EVH (open bar) between visits. Panel b). Urinary $9 \alpha, 11 \beta$ - prostaglandin $\mathrm{F}_{2}$ pre EVH (closed bar) and 60 min post EVH (open bar) between visits. ${ }^{*}$ denotes significant difference pre-EVH between condition $(P<0.05)$. ${ }^{\#}$ denotes significant difference post-EVH between condition $400 \quad(P<0.05)$.

401

402

403

404

405

406

407

408

409

410

411

412 


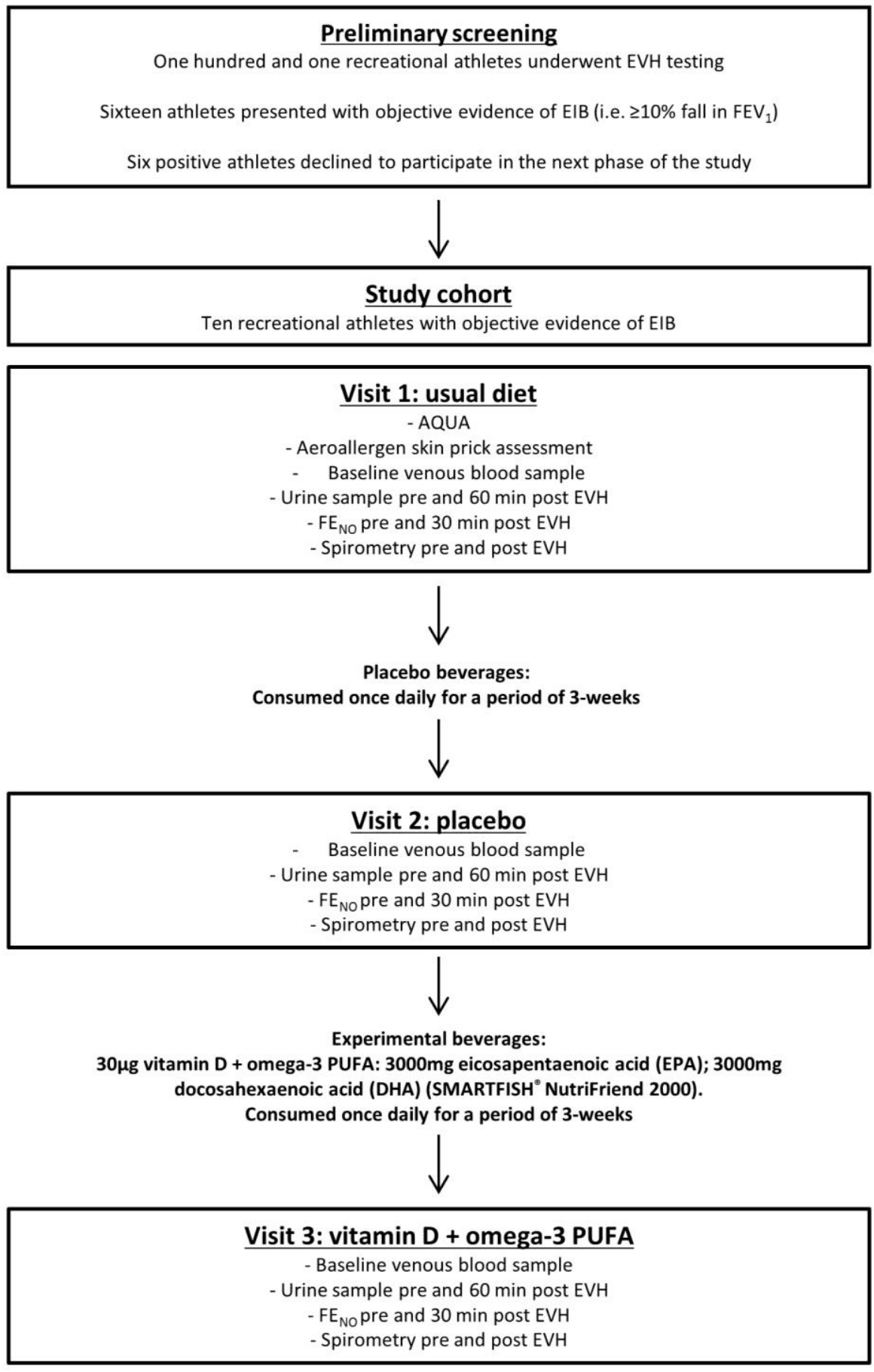

$415 \quad$ Figure 1. 


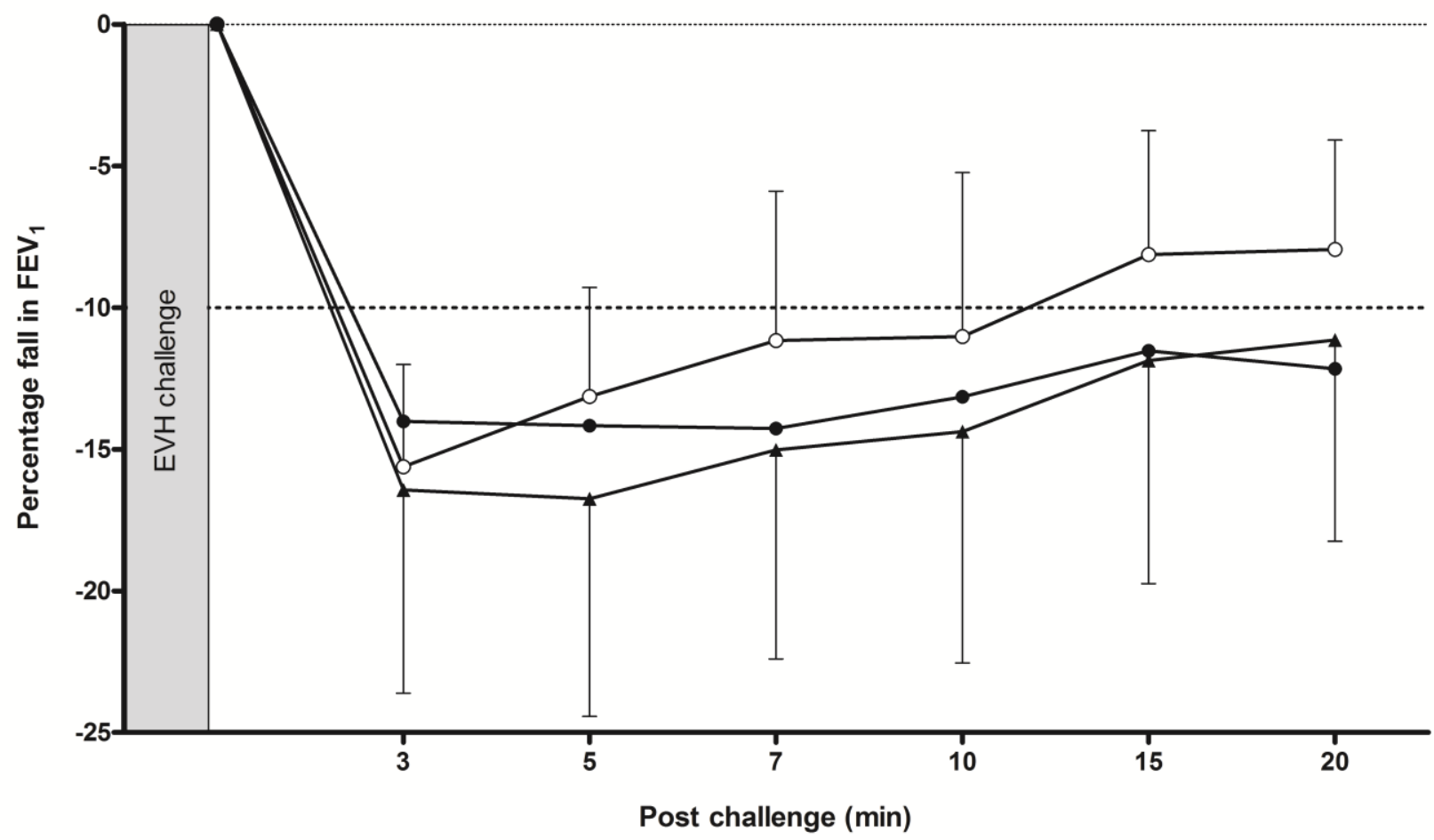

416

417 Figure 2.

418 


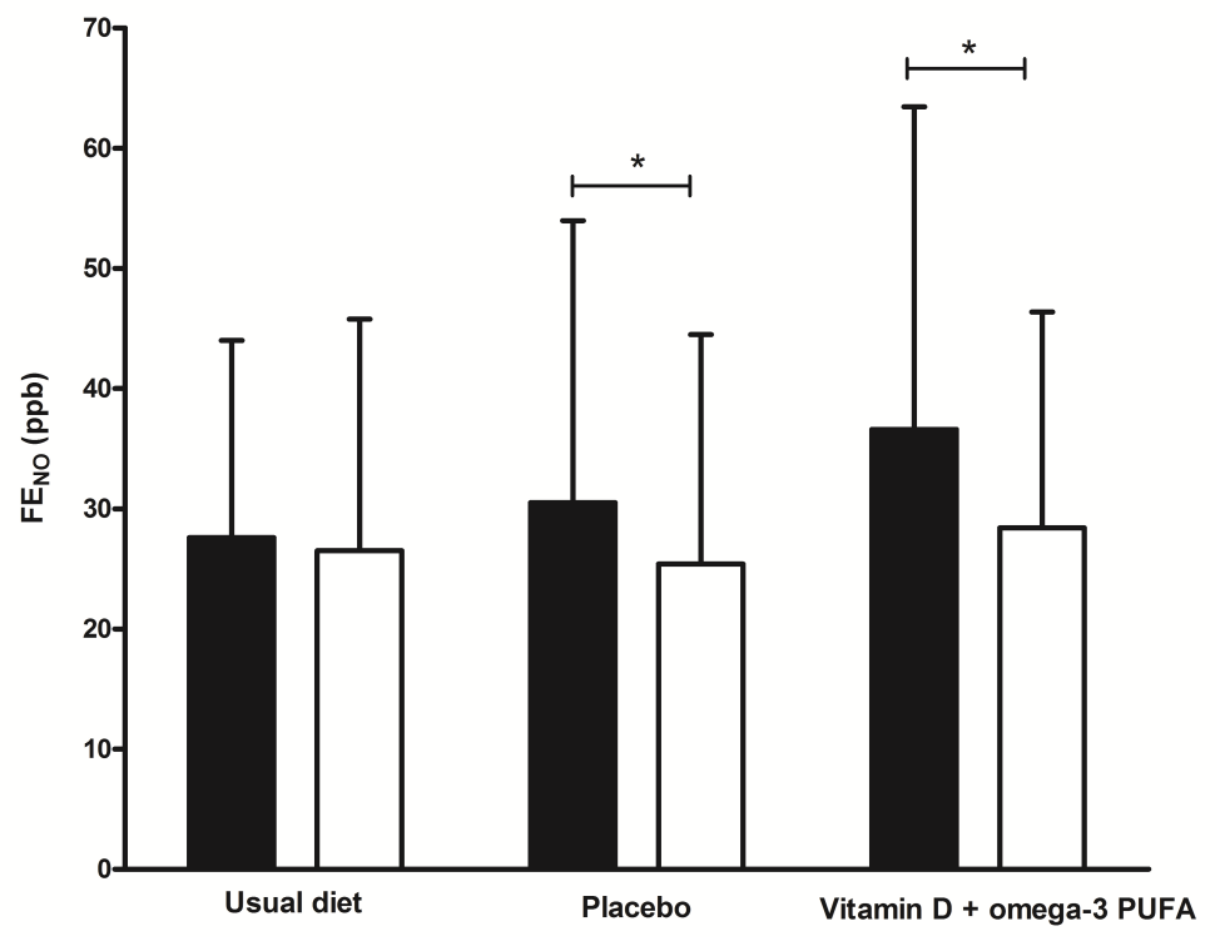

$421 \quad$ Figure 3.

422 
a)

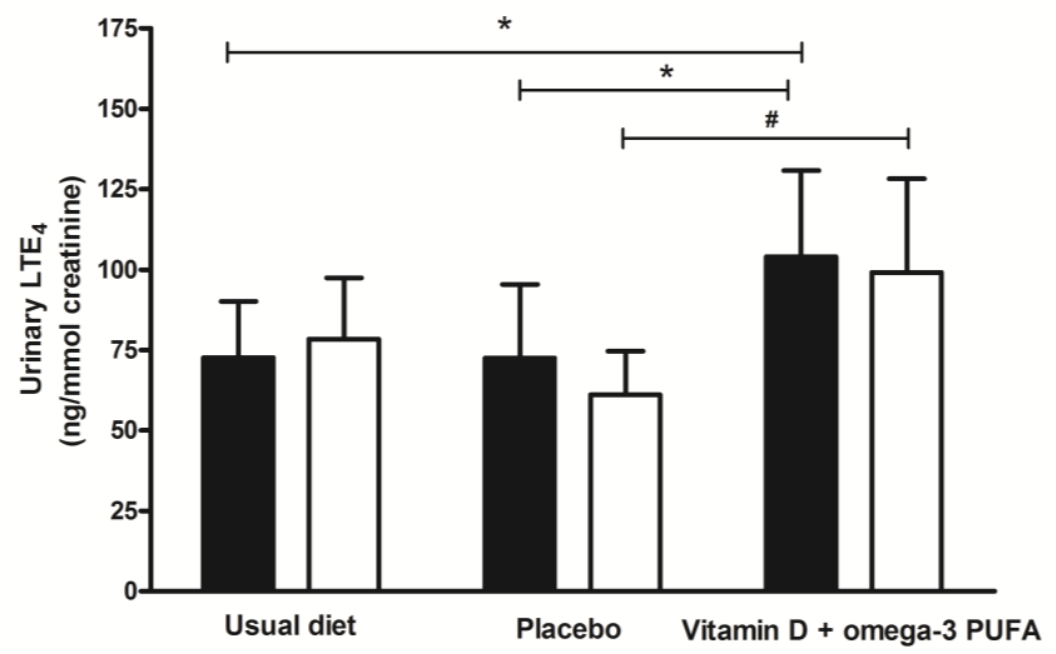

b)

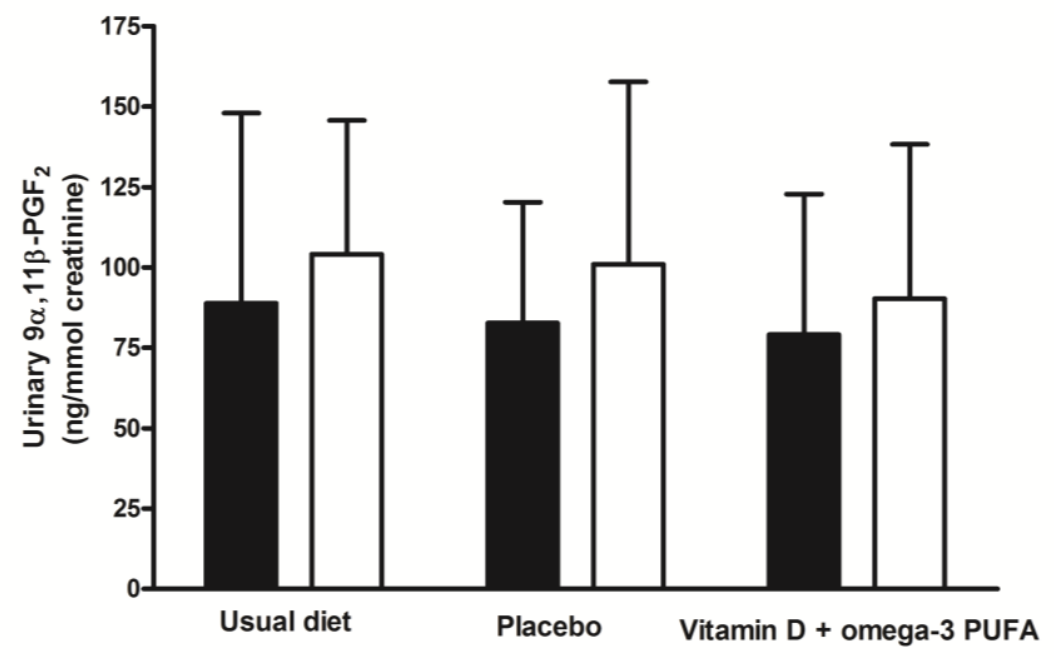

424

$425 \quad$ Figure 4.

426 
428

429

430

431

432

433

434

435

436

437

438

439

440

441

442

443

444

445

446

447

448

449

450

451

452

453

454

455

456

457

458

459

460

461

462

463

464

465

466

467

468

469

470

471

472

473

474

1. Parsons JP, Hallstrand TS, Mastronarde JG et al. An official American Thoracic Society clinical practice guideline: exercise-induced bronchoconstriction. Am J Respir Crit Care Med, 187(9), 1016-1027 (2013).

2. Price OJ, Ansley L, Menzies-Gow A, Cullinan P, Hull JH. Airway dysfunction in elite athletes-an occupational lung disease? Allergy, 68(11), 1343-1352 (2013).

3. Molphy J, Dickinson J, Hu J, Chester N, Whyte G. Prevalence of bronchoconstriction induced by eucapnic voluntary hyperpnoea in recreationally active individuals. Journal of Asthma, 51(1), 45-50 (2014).

4. Kippelen P, Anderson SD. Pathogenesis of Exercise-Induced Bronchoconstriction. Immunology and allergy clinics of North America, 33(3), 299-312 (2013).

5. Hallstrand TS, Altemeier WA, Aitken ML, Henderson WR. Role of Cells and Mediators in Exercise-Induced Bronchoconstriction. Immunology And Allergy Clinics of North America, 33(3), 313-328 (2013).

6. Karjalainen E, Laitinen A, Sue-Chu M, Altraja A, Bjermer L, Laitinen LA. Evidence of airway inflammation and remodeling in ski athletes with and without bronchial hyperresponsiveness to methacholine. Am J Respir Crit Care Med, 161(6), 2086 (2000).

7. Davis MS, Schofield B, Freed AN. Repeated peripheral airway hyperpnea causes inflammation and remodeling in dogs. Medicine \& Science in Sports \& Exercise, 35(4), 608-616 (2003).

8. Mickleborough TD. A nutritional approach to managing exercise-induced asthma. Exercise and sport sciences reviews, 36(3), 135-144 (2008).

9. Wraight JM, Smith AD, Cowan JO, Flannery EM, Herbison GP, Taylor DR. Adverse effects of short-acting beta-agonists: Potential impact when anti-inflammatory therapy is inadequate. Respirology, 9(2), 215-221 (2004).

10. Mickleborough TD, Lindley MR, Ionescu AA, Fly AD. Protective effect of fish oil supplementation on exercise-induced bronchoconstriction in asthma. CHEST Journal, 129(1), 39-49 (2006).

11. Mickleborough TD, Murray RL, Ionescu AA, Lindley MR. Fish oil supplementation reduces severity of exercise-induced bronchoconstriction in elite athletes. Am J Respir Crit Care Med, 168(10), 1181-1189 (2003).

12. Mickleborough TD, Vaughn CL, Shei R-J, Davis EM, Wilhite DP. Marine lipid fraction PCSO-524 ${ }^{\mathrm{TM}}($ lyprinol $<\sup >\AA</$ sup $>$ /omega $\mathrm{XL}<\sup >\AA</$ sup $>$ ) of the New Zealand green lipped mussel attenuates hyperpnea-induced bronchoconstriction in asthma. Respir Med, 107(8), 1152-1163 (2013). 
13. Head S, Mickleborough T. Randomized Cross-Over Controlled Pilot Study of Docosahexaenoic Acid Supplementation on Airway Inflammation and HyperpneaInduced Bronchoconstriction in Adults with Asthma. The Internet Journal of Asthma, Allergy and Immunology, 9(1) (2013).

14. Williams N, Hunter K, Johnson M, Sharpe G. A randomised placebo controlled trial to compare the effects of two dosages of omega-3 PUFA on exercise-induced bronchoconstriction (EIB). Br J Sports Med, 47(17), e4-e4 (2013).

15. Brannan JD, Bood J, Alkhabaz A et al. The effect of omega-3 fatty acids on bronchial hyperresponsiveness, sputum eosinophilia and mast cell mediators in asthma. CHEST Journal, (2014).

16. Arm J, Horton C, Mencia-Huerta $\mathrm{J}$ et al. Effect of dietary supplementation with fish oil lipids on mild asthma. Thorax, 43(2), 84-92 (1988).

17. Mickleborough T, Rundell K. Dietary polyunsaturated fatty acids in asthma-and exercise-induced bronchoconstriction. European journal of clinical nutrition, 59(12), 1335-1346 (2005).

18. Foong RE, Zosky GR. Vitamin D deficiency and the lung: disease initiator or disease modifier? Nutrients, 5(8), 2880-2900 (2013).

19. Chinellato I, Piazza M, Sandri M et al. Serum vitamin D levels and exercise-induced bronchoconstriction in children with asthma. Eur Respir J, 37(6), 1366-1370 (2011).

20. Toyota N, Sakai H, Takahashi H, Hashimoto Y, Iizuka H. Inhibitory effect of $1 \alpha, 25-$ dihydroxyvitamin D3 on mast cell proliferation and A23187-induced histamine release, also accompanied by a decreased c-kit receptor. Archives of dermatological research, 288(11), 709-715 (1996).

21. Baroni E, Biffi M, Benigni F et al. VDR-dependent regulation of mast cell maturation mediated by 1, 25-dihydroxyvitamin D3. Journal of leukocyte biology, 81(1), 250-262 (2007).

22. Benigni $\mathrm{F}$, Baroni $\mathrm{E}$, Zecevic $\mathrm{M}$ et al. Oral treatment with a vitamin D3 analogue (BXL628) has anti-inflammatory effects in rodent model of interstitial cystitis. BJU international, 97(3), 617-624 (2006).

23. Bosse Y, Maghni K, Hudson TJ. 1alpha,25-dihydroxy-vitamin D3 stimulation of bronchial smooth muscle cells induces autocrine, contractility, and remodeling processes. Physiol Genomics, 29(2), 161-168 (2007).

24. Berraies A, Hamzaoui K, Hamzaoui A. Link between vitamin D and airway remodeling. Journal of asthma and allergy, 7, 23-30 (2014).

25. International Olympic Commitee - Medical Commission. Beta2 adrenoceptor agonists and the Olympic Games in Beijing. Available at: http://www.olympic.org/Documents/Reports/EN/en_report_1302.pdf (accessed 14 Aug 2014) (2008). 
26. Jones G. Pharmacokinetics of vitamin D toxicity. The American journal of clinical nutrition, 88(2), 582S-586S (2008).

27. Choi IS, Ki W-J, Kim T-O, Han E-R, Seo I-K. Seasonal factors influencing exerciseinduced asthma. Allergy, asthma \& immunology research, 4(4), 192-198 (2012).

28. Bousquet J, Heinzerling L, Bachert C et al. Practical guide to skin prick tests in allergy to aeroallergens. Allergy, 67(1), 18-24 (2012).

29. Bonini M, Braido F, Baiardini I et al. AQUA: allergy questionnaire for athletes. Development and validation. Med Sci Sports Exerc, 41(5), 1034-1041 (2009).

30. Miller MR, Hankinson J, Brusasco V et al. Standardisation of spirometry. Eur Respir $J, 26(2), 319-338$ (2005).

31. Ansley L, Kippelen P, Dickinson J, Hull J. Misdiagnosis of exercise-induced bronchoconstriction in professional soccer players. Allergy, 67(3), 390-395 (2012).

32. Argyros GJ, Roach JM, Hurwitz KM, Eliasson AH, Phillips YY. Eucapnic voluntary hyperventilation as a bronchoprovocation technique. Chest, 109(6), 1520-1524 (1996).

33. American Thoracic Society/European Respiratory Society recommendations for standardized procedures for the online and offline measurement of exhaled lower respiratory nitric oxide and nasal nitric oxide, 2005. Am J Respir Crit Care Med, 171(8), 912-930 (2005).

34. Emmen J, Wielders JP, Boer A-K, van den Ouweland JM, Vader HL. The new Roche Vitamin D Total assay: fit for its purpose? Clinical Chemistry and Laboratory Medicine, 50(11), 1969-1972 (2012).

35. Holick MF. Vitamin D deficiency. New England Journal of Medicine, 357(3), 266281 (2007).

36. Tecklenburg-Lund S, Mickleborough TD, Turner LA, Fly AD, Stager JM, Montgomery GS. Randomized controlled trial of fish oil and montelukast and their combination on airway inflammation and hyperpnea-induced bronchoconstriction. PloS one, 5(10), e13487 (2010).

37. Kippelen P, Larsson J, Anderson SD, Brannan JD, Dahlén B, Dahlén SE. Effect of sodium cromoglycate on mast cell mediators during hyperpnea in athletes. Med Sci Sports Exerc, 42(10), 1853-1860 (2010).

38. Bartels H, Böhmer M, Heierli C. Serum creatinine determination without protein precipitation. Clinica chimica acta; international journal of clinical chemistry, 37, 193-197 (1972).

39. Anderson S, Argyros G, Magnussen H, Holzer K. Provocation by eucapnic voluntary hyperpnoea to identify exercise induced bronchoconstriction. Br J Sports Med, 35(5), 344-347 (2001). 
601

602

603

604

605

606

607

608

609

610

611

612

613

614

615

616

617

618

619

620

621

622
40. Scragg R, Camargo CA. Frequency of leisure-time physical activity and serum 25hydroxyvitamin D levels in the US population: results from the Third National Health and Nutrition Examination Survey. American journal of epidemiology, 168(6), 577586 (2008).

41. Black PN, Scragg R. Relationship between serum 25-hydroxyvitamin d and pulmonary function in the third national health and nutrition examination survey. CHEST Journal, 128(6), 3792-3798 (2005).

42. Devereux G, Wilson A, Avenell A, McNeill G, Fraser W. A case-control study of vitamin D status and asthma in adults. Allergy, 65(5), 666-667 (2010).

43. Bar Yoseph R, Livnat G, Schnapp Z et al. The effect of vitamin D on airway reactivity and inflammation in asthmatic children: A double-blind placebo-controlled trial. Pediatric pulmonology, (2014).

44. Owens DJ, Fraser WD, Close GL. Vitamin D and the athlete: Emerging insights. Eur J Sport Sci, 15(1), 73-84 (2015).

45. Moreira A, Moreira P, Delgado L et al. Pilot study of the effects of $\mathrm{n}-3$ polyunsaturated fatty acids on exhaled nitric oxide in patients with stable asthma. Journal of investigative allergology and clinical immunology, 17(5), 309-313 (2007).

46. Rundell KW, Anderson SD, Spiering BA, Judelson DA. Field exercise vs laboratory eucapnic voluntary hyperventilation to identify airway hyperresponsiveness in elite cold weather athletes. CHEST Journal, 125(3), 909-915 (2004).

47. Dickinson J, Whyte G, McConnell A, Harries M. Screening elite winter athletes for exercise induced asthma: a comparison of three challenge methods. Br J Sports Med, 40(2), 179-182 (2006).

48. Schuster GU, Bratt JM, Jiang X et al. Dietary Long-Chain Omega-3 Fatty Acids Do Not Diminish Eosinophilic Pulmonary Inflammation in Mice. American journal of respiratory cell and molecular biology, 50(3), 626-636 (2014).

49. Anderson SD, Pearlman DS, Rundell KW et al. Reproducibility of the airway response to an exercise protocol standardized for intensity, duration, and inspired air conditions, in subjects with symptoms suggestive of asthma. Respir Res, 11(120) (2010).

50. Price OJ, Ansley L, Hull JH. Diagnosing Exercise-Induced Bronchoconstriction With Eucapnic Voluntary Hyperpnea: Is One Test Enough? The Journal of Allergy and Clinical Immunology: In Practice, (2014).

51. Gupta A, Sjoukes A, Richards D et al. Relationship between serum vitamin D, disease severity, and airway remodeling in children with asthma. Am J Respir Crit Care Med, 184(12), 1342-1349 (2011). 
REFERENCE ANNOTATIONS

625

626

627

628

629

630

631

632

633

634

635

636

637

638

639

640

641

642

643

644

645

646

647

648

649

650

651

652

653

654

655

656

657

658

659

660

661

662

663

664

\section{References of considerable interest ${ }^{* *}$}

${ }^{* * *}$ Chinellato I, Piazza M, Sandri M et al. Serum vitamin D levels and exerciseinducedbronchoconstriction in children with asthma. Eur Respir J, 37(6), 1366-1370 (2011).

First study to show a relationship between low serum vitamin D levels and severity of EIB in asthmatic children.

**Arm J, Horton C, Mencia-Huerta J et al. Effect of dietary supplementation with fish oil lipids on mild asthma. Thorax, 43(2), 84-92 (1988).

Early work indicating no beneficial effect of omega-3 PUFA supplementation in patients with mild asthma.

***Mickleborough TD, Murray RL, Ionescu AA, Lindley MR. Fish oil supplementatio reduces severity of exercise-induced bronchoconstriction in elite athletes. Am J Respir Crit Care Med,168(10), 1181-1189 (2003).

Fish oil supplementation (i.e. omega-3 PUFA) provides a protective effect in suppressing EIB in elite athletes due to their anti-inflammatory properties.

${ }^{* * *}$ Mickleborough TD, Lindley MR, Ionescu AA, Fly AD. Protective effect of fish oil supplementation on exercise-induced bronchoconstriction in asthma. CHEST Journal, 129(1), 39-49 (2006).

Fish oil supplementation (i.e. omega-3 PUFA) provides a protective effect in suppressing EIB in elite athletes with asthma.

***Bannan JD, Bood J, Alkhabaz A et al. The effect of omega-3 fatty acids on bronchial hyperresponsiveness, sputum eosinophilia and mast cell mediators in asthma. CHEST Journal, (2014).

Omega-3 supplementation does not improve bronchial hyper-responsivesness to mannitol or inhibit urinary inflammatory mediator excretion in adults with mild-moderate asthma. 
666 "Parsons JP, Hallstrand TS, Mastronarde JG et al. An Official American Thoracic Society 667 Clinical Practice Guideline: Exercise-induced Bronchoconstriction. Am J Respir Crit Care 668 Med, 187(9), 1016-1027 (2013).

669 The recent American Thoracic Society guidelines concluded that whilst it is reasonable to 670 employ omega-3 PUFA supplementation in receptive patients with EIB, the evidence is not 671 currently strong enough to suggest that they are effective in a large majority cases.

672

673

674 "Tecklenburg-Lund S, Mickleborough TD, Turner LA, Fly AD, Stager JM, Montgomery GS.

675 Randomized controlled trial of fish oil and montelukast and their combination on airway 676 inflammation and hyperpnea-induced bronchoconstriction. PloS one, 5(10), e13487 (2010).

677

678

679

680

681

682

*Mickleborough TD, Vaughn CL, Shei R-J, Davis EM, Wilhite DP. Marine lipid fraction 683 PCSO-524 $4^{\mathrm{TM}}($ lyprinol $<\sup >\AA</$ sup $>$ /omega $\mathrm{XL}<\sup >\AA</$ sup $>$ ) of the New Zealand green 684 lipped mussel attenuates hyperpnea-induced bronchoconstriction in asthma. Respir Med, 685 107(8), 1152-1163 (2013).

686

687

688

689

Bronchoconstrictor response to EVH attenuated following fish oil supplementation (i.e. omega-3 PUFA) in asthmatic patients with EIB.

Bronchoconstrictor response to EVH attenuated following omega-3 PUFA supplementation derived from New Zealand green lipped mussel (Perna canaliculus)in asthmatic patients with EIB. 


\section{ACKNOWLEDGEMENTS}

Nil.

\section{FUNDING STATEMENT}

Dietary supplements were provided by Smartfish ${ }^{\circledR}$ Medical Nutrition. All other funding was provided by Northumbria University.

\section{COMPETING INTERESTS}

The authors have no real or perceived conflict of interest in respect of this manuscript.

\section{GUARANTOR STATEMENT}

OP confirms full responsibility for the content of the manuscript, including data and analysis.

\section{CONTRIBUTION STATEMENT}

OP was involved in the conception and design of the study, acquisition, interpretation of data, drafting and critical revision of manuscript and final approval of the version to be published.

$\mathrm{JH}$ was involved in the conception and design of the study, interpretation of data, drafting and critical revision of manuscript and final approval of the version to be published

GH was involved in the conception and design of the study, drafting and critical revision of manuscript and final approval of the version to be published.

PA was involved in the conception and design of the study, drafting and critical revision of manuscript and final approval of the version to be published.

LA was involved in the conception and design of the study, interpretation of data, drafting and critical revision of manuscript and final approval of the version to be published 